\title{
Unexpected tracheal narrowing during general anesthesia in the prone position of Duchenne muscular dystrophy patient
}

\section{-A report of two cases-}

\author{
Dong Kyu Lee, Byung Gun Lim, Il-Ok Lee, Hye-Ran Oh, Sang Ho Lim, and Mi Kyoung Lee
}

Department of Anesthesiology and Pain Medicine, Korea University Guro Hospital, Seoul, Korea

Unexpected tracheal narrowing was observed in a patient with Duchenne muscular dystrophy during a corrective operation for thoracolumbar scoliosis. As the operating time progressed, peak airway pressure and end-tidal $\mathrm{CO}_{2}$ increased gradually in the prone position. We found a floppy portion of the trachea using fiberoptic bronchoscopy (FB) in the prone position. We advanced a wire-reinforced tube toward the carina beyond the lesion. This allowed correction of the ventilatory abnormalities. We encountered another patient scheduled for the same operation. We performed FB in advance before the position change and observed a narrowed portion of trachea. We advanced the tracheal tube under FB beyond the pathologic portion and then moved the patient into the prone position. The operation was done successfully without any problems. (Korean J Anesthesiol 2013; 64: 456-459)

Key Words: Duchenne muscular dystrophy, Prone position, Tracheal narrowing.

Duchenne muscular dystrophy (DMD) is associated with a number of anesthetic problems including malignant hyperthermia, difficult intubation, upper airway obstruction and decreased lung function due to thoracolumbar scoliosis [1]. Upper airway obstruction can occur during surgery in DMD patients who experience difficult respiration in their daily lives [2]. But we found unexpected floppy tracheal wall during operations in DMD patients who did not report symptoms of respiration insufficiency in their daily life.

Thus we describe two cases of an unexpected tracheal narrowing during general anesthesia for the correction of scoliosis in DMD patients lying in the prone position, and how we successfully managed these potentially problematic situations with a simple measure.

\section{Case Reports}

Written statements granting permission of publication for the following cases were obtained from the parents or caregivers of the patients in nursing homes.

Received: July 13, 2012. Revised: July 27, 2012. Accepted: August 1, 2012.

Corresponding author: Mi Kyoung Lee, M.D., Ph.D., Department of Anesthesiology and Pain medicine, Korea University Guro Hospital, Guro 2-dong, Guro-gu, Seoul 152-703, Korea. Tel: 82-2-2626-1870, Fax: 82-2-851-9897, E-mail: mknim@hotmail.com

(c) This is an open-access article distributed under the terms of the Creative Commons Attribution Non-Commercial License (http:// creativecommons.org/licenses/by-nc/3.0/), which permits unrestricted non-commercial use, distribution, and reproduction in any medium, provided the original work is properly cited. 


\section{Case 1}

A 12-year-old boy (height $125 \mathrm{~cm}$, weight $18.8 \mathrm{~kg}$ ) with Duchenne muscular dystrophy (DMD) was scheduled for the correction of thoracolumbar scoliosis. Cobb's angle was $100^{\circ}$. Preoperative evaluation revealed that he was acceptable for general anesthesia, but he had decreased lung function. The $\mathrm{FEV}_{1} 0.66$ liter, /FVC 0.73 liter, $\mathrm{FEV}_{1} / \mathrm{FVC}$ 90\%). He did not report any symptoms of insufficient respiration in his daily life. He was supported on the operating table with multiple padding due to scoliosis and posterolaterally bent neck. Anesthesia was induced intravenously with propofol and rocuronium, and he was then intubated successfully with a wire-reinforced tracheal tube (internal dimension $5.5 \mathrm{~mm}$, SPIRAL-FLEX ${ }^{\circledR}$ reinforced tubes, Hudson RCI, Temecula, USA). The tracheal tube was fixed at $17 \mathrm{~cm}$. Both lung sounds were clear with manual ventilation. Peak inspiratory pressure (PIP) was 16 $\mathrm{cmH}_{2} \mathrm{O}$ with volume-controlled mechanical ventilation, tidal volume (TV) $160 \mathrm{ml}$, respiration rate (RR) 16 per minute and $\mathrm{FiO}_{2}$ 0.5. Anesthesia was maintained with intravenous propofol and remifentanil starting at the targeted effect concentration of $3 \mu \mathrm{g} / \mathrm{ml}$ and $3.5 \mathrm{ng} / \mathrm{ml}$ respectively via target controlled infusion (TCI). After internal jugular vein and radial artery catheterization, the patient was moved into the prone position. In the prone position, PIP reached up to $30 \mathrm{cmH}_{2} \mathrm{O}$, and a lowpitched wheezing sound was detected in both lungs, although no secretion was observed from suctioning via tracheal tube. We switched the ventilator mode from the volume-controlled type to the pressure-controlled type. The expirated TV ranged between 160-200 ml with set pressure at $25 \mathrm{cmH}_{2} \mathrm{O}$ and $\mathrm{RR} 15$ per minute. In this setting, arterial blood gas analysis (ABGA) was pH 7.43, $\mathrm{PaO}_{2} 226 \mathrm{mmHg}$, and $\mathrm{PaCO}_{2} 34 \mathrm{mmHg}$. A few minutes later, the expired TV gradually dropped to 120-140 $\mathrm{ml}$ at the same pressure-controlled ventilator setting. End tidal carbon dioxide concentration $\left(\mathrm{EtCO}_{2}\right)$ increased gradually up to $50 \mathrm{mmHg}$. ABGA were at $\mathrm{pH} 7.25, \mathrm{PO}_{2} 224 \mathrm{mmHg}$ and $\mathrm{PCO}_{2}$ $60 \mathrm{mmHg}$. At this point, we decided to perform a fiberoptic bronchoscopy (LF-P, Intubation fiberscope, Olympus, Tokyo, Japan; FB). We found a narrowed, non pulsatile and nearly kissing tracheal wall between the carina and the tip of the tracheal tube using FB. Under the fiberscope guide, a wirereinforced tracheal tube was advanced over the narrowed portion of the trachea, and we fixed the tube at $20.5 \mathrm{~cm}$. The tip of the tracheal tube was placed just above the carina. Afterwards, with TV $160 \mathrm{ml}$, RR 16 per minute in the volumecontrolled ventilation mode, PIP maintained below $20 \mathrm{cmH}_{2} \mathrm{O}$, and $\mathrm{EtCO}_{2}$ was about $25 \mathrm{mmHg}$. The lung sounds of both lung fields were clear, so the remaining surgical procedure was done. At the end of the surgery, we changed the patient to the supine position. We set back the wire-reinforced tube to the previous position $(17 \mathrm{~cm})$ and observed the narrowed portion of trachea using FB. The narrowest part was acceptable for ventilation during positive ventilation and spontaneous respiration after the position change into supine. The emergence from general anesthesia was smooth without any complications.

\section{Case 2}

A 14 year-old male patient (height $158 \mathrm{~cm}$, weight $50 \mathrm{~kg}$ ) was scheduled to receive a corrective operation for thoracolumbar scoliosis. He also was diagnosed with DMD in his early childhood. When he was 9 years old, he started a wheelchair life due to muscle weakness. Preoperative evaluation revealed thoracolumbar scoliosis (Cobb's angle $70^{\circ}$ ) and decreased lung function $\left(\mathrm{FEV}_{1} 0.86\right.$ liter, FVC 1.37 liter, $\left.\mathrm{FEV}_{1} / \mathrm{FVC} 63 \%\right)$. Except for these findings, all the other tests were in the normal range. He did not report any respiratory problems in his daily life. Anesthesia induction was performed with propofol, remifentanil, and a small dose of a rocuronium. The tracheal intubation was successful with a wire-reinforced tube. Airway
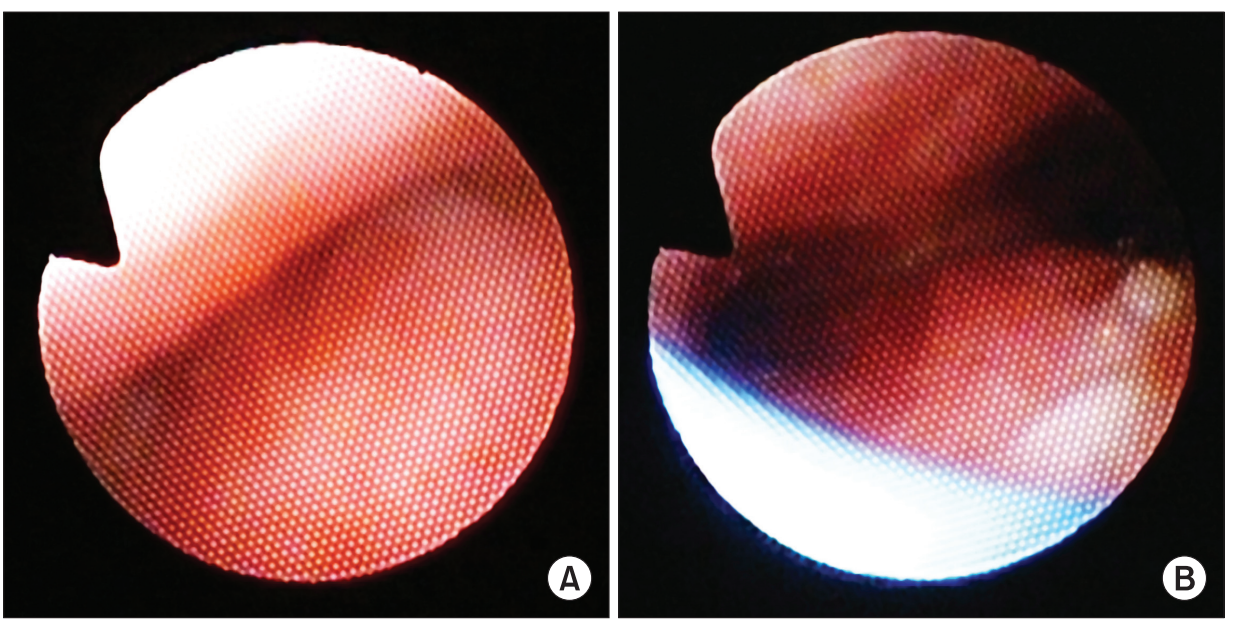

Fig. 1. Fiberoptic bronchoscopic findings of the second case patient in the supine position. (A) A tracheal obstruction was observed in the mid-tracheal area. (B) Under bronchoscopic guidance, a tracheal tube was advanced to just above the carina. Thus tracheal patency was maintained in both the prone and supine position. 
pressures during controlled ventilation fell into normal range. But we immediately performed FB and observed a narrowed portion beyond the tip of the tracheal tube until the closing at the carina (Fig. 1). We advanced the tracheal tube along the fiberscope until its tip reached the carina. The sounds of both lung fields were clear. In the volume controlled ventilation mode (expired TV $400 \mathrm{ml}$, RR 13 per minute, $\mathrm{FiO}_{2}$ 0.5), PIP was $18 \mathrm{cmH}_{2} \mathrm{O}$, and $\mathrm{EtCO}_{2}$ was $28 \mathrm{mmHg}$. After the patient was put into the prone position, we did FB again. It revealed the patency of the tracheal lumen in the prone position. During the operation, PIP maintained at a range of $22-26 \mathrm{cmH}_{2} \mathrm{O}$ without $\mathrm{CO}_{2}$ retention. The surgery ended without any problems and at the end of anesthesia, FB confirmed the airway as narrow but acceptable for ventilation with retrieved endotracheal tube. During emergence and in the recovery room, the patient did not suffer from airway problems.

\section{Discussion}

DMD is the most common muscular dystrophy in children $[1,3]$. The disease process includes progressive degeneration of the skeletal, cardiac and smooth muscles. The anesthetic problems of DMD we may be confronted with are respiratory and cardiac complications, rhabdomyolysis, and malignant hyperthermia $[1,2]$. DMD patients usually present with concurrent pulmonary diseases preoperatively, and they are more susceptible to respiratory complications $[4,5]$. These complications range from minimal atelectasis to pulmonary edema and respiratory failure [4].

Tracheal obstruction, an unusual respiratory complication, has been reported before, and it was related to corrective scoliosis surgery in musculoskeletal diseases including
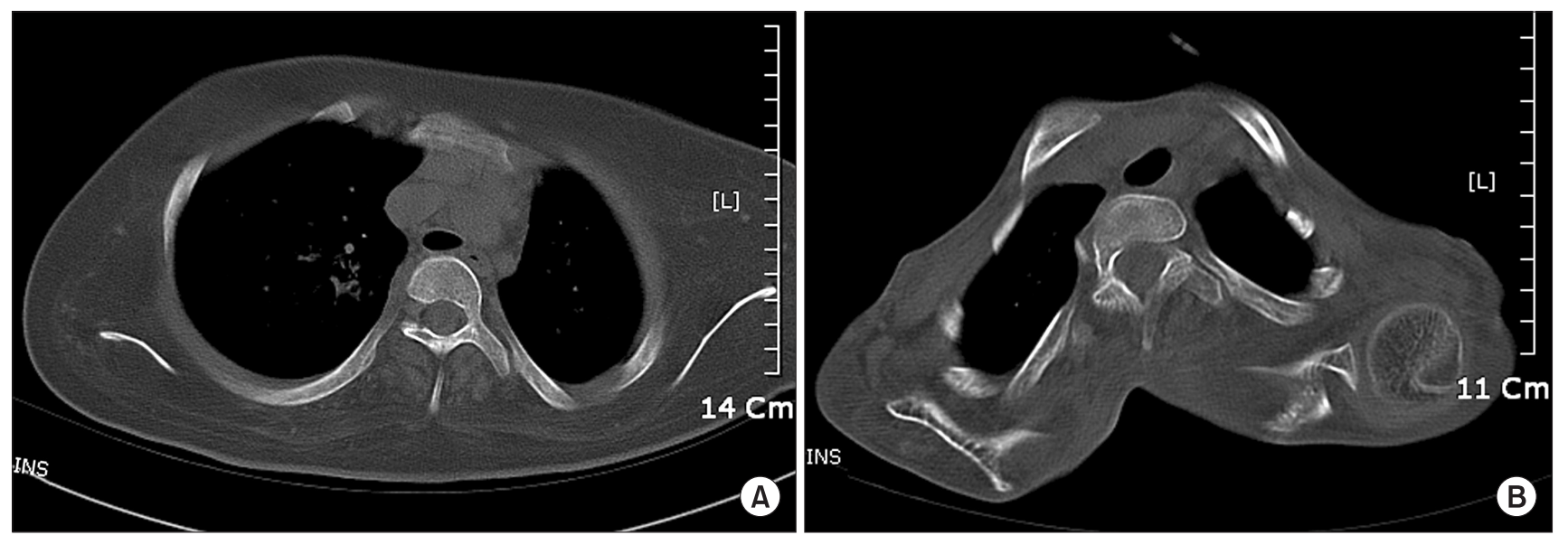

Fig. 2. Computed tomography of the patient in case 1 (A) and 2 (B). All patients represented compressed and narrowed tracheal lumen at variable upper thoracic vertebrae levels. Thoracic vertebrae deformity resulted in distorted bony structure which support mediastinal contents. In this situation, prone positioning and surgical manipulation over the thoracic vertebrae could aggravate tracheal narrowing.
$[2,6,7]$. Thoracolumbar scoliosis, a kind of abnormal thoracic configuration, may be related to tracheal obstruction, which results in an obstructive airway pattern in a pulmonary function test [8]. In thoracolumbar scoliosis, the deformity of the spine decreases the distance from the sternum to the thoracic vertebrae [9]. Moreover, corrective surgeries for scoliosis are usually performed in the prone position, and tracheal obstruction worsens with compressive pressure of the screw fixations. Additional deterioration of the spine curvature by corrective operation changes the structure of the mediastinum, and tracheal obstruction can be worsened by angulation, stretching, and the compression of vertebrae [10].

In the two cases listed above, although the patients had decreased lung function due to muscle weakness, they had no respiratory difficulty in their daily life. In the first patient, ABGA was tolerable at first, but it gradually worsened over time. We performed FB and found a narrowed, pulseless, nearly kissing tracheal wall. Then we advanced the wire-reinforced tracheal tube over the lesion in the prone position, and we solved the ventilatory problems. In the second case, we performed FB immediately after anesthesia induction based on the first experience. We also found partial tracheal obstruction and corrected it.

The problem we can expect with this maneuver includes accidental one-lung ventilation and mucosal edema of narrowed trachea. During corrective scoliosis surgery, the changes of thoracolumbar spine curvature could produce morphologic changes of tracheobroncheal trees. Because we advanced the endotracheal tube until the tip of tube reached near the carina, unintentional one-lung ventilation could occur but fortunately did not. The second, the cuff or endotracheal 
tube itself could be a cause of mechanical irritation over the narrowed portion; mucosal edema could develop resulting in respiratory problems after extubation. To prevent this possible complication, we performed FB at the end of anesthesia with retrieved endotracheal tube depth and confirmed adequate patency of the narrowed tracheal portion and normal mucosal appearance. Maintaining adequate cuff pressure of the endotracheal tube and medication which reduces mucosal edema including steroids is recommended. Moreover, FB before extubation is highly recommended to prevent this complication.

We reviewed computed tomography of these patients to find predictive signs of tracheal obstruction which developed during general anesthesia, but not at other times. Usually the narrowest portion of mediastinum is around the manubrium level; the bony structures protect mediastinal contents from external forces. But these patients suffered compressed tracheal lumen around third or fourth thoracic vertebrae. At these levels, the bony support of the mediastinal structure was not usual because of the anatomical deformities including thoracic scoliosis (Fig. 2). In this situation, tracheal obstruction could develop in the prone position even though the patient did not have any prior respiratory problems.

In conclusion, when patients who have muscle weakness like DMD are scheduled for a surgical procedure in the prone position, FB is strongly recommended even though patients have no clinical symptoms and signs of respiratory insufficiency experienced in their daily life. Pre-operative imaging study and intraoperative FB help the anesthesiologist to recognize unexpected tracheal narrowing and that we would place the endotracheal tube at a proper depth to overcome tracheal narrowing.

\section{References}

1. Morris P. Duchenne muscular dystrophy: a challenge for the anaesthetist. Paediatr Anaesth 1997; 7: 1-4.

2. Okuda Y, Sato H, Kitajima T, Asai T. Airway obstruction during general anaesthesia in a child with congenital tracheomalacia. Eur J Anaesthesiol 2000; 17: 642-4.

3. Hayes J, Veyckemans F, Bissonnette B. Duchenne muscular dystrophy: an old anesthesia problem revisited. Paediatr Anaesth 2008; 18: 100-6.

4. Modi HN, Suh SW, Hong JY, Cho JW, Park JH, Yang JH. Treatment and complications in flaccid neuromuscular scoliosis (Duchenne muscular dystrophy and spinal muscular atrophy) with posterioronly pedicle screw instrumentation. Eur Spine J 2010; 19: 384-93.

5. Barsdorf AI, Sproule DM, Kaufmann P. Scoliosis surgery in children with neuromuscular disease: findings from the US National Inpatient Sample, 1997 to 2003. Arch Neurol 2010; 67: 231-5.

6. Rittoo DB, Morris P. Tracheal occlusion in the prone position in an intubated patient with Duchenne muscular dystrophy. Anaesthesia 1995; 50: 719-21.

7. Oh AY, Kim YH, Kim BK, Kim HS, Kim CS. Unexpected tracheomalacia in Marfan syndrome during general anesthesia for correction of scoliosis. Anesth Analg 2002; 95: 331-2.

8. Donnelly LF, Bisset GS 3rd. Airway compression in children with abnormal thoracic configuration. Radiology 1998; 206: 323-6.

9. Bagshaw ON, Jardine A. Cardiopulmonary complications during anaesthesia and surgery for severe thoracic lordoscoliosis. Anaesthesia 1995; 50: 890-2.

10. Al-Kattan K, Simonds A, Chung KF, Kaplan DK. Kyphoscoliosis and bronchial torsion. Chest 1997; 111: 1134-7. 